\title{
Corrosion resistance of steel for coiled tubing units
}

\author{
Andriy Syrotyuk ${ }^{1}$, Oleg Vytyaz ${ }^{2}$, Rostyslav Leshchak ${ }^{1}$, and Jan Ziaja ${ }^{3}$ \\ ${ }^{1}$ Karpenko Physico-Mechanical Institute of the National Academy of Sciences of Ukraine, \\ Department of Strength of Materials and Structures in Hydrogen-Containing Environments, \\ 5 Naukova St, 79060, Lviv, Ukraine \\ ${ }^{2}$ Ivano-Frankivsk National Technical University of Oil and Gas, Institute of Petroleum Engineering, \\ 15 Karpatska St, 76019, Ivano-Frankivsk, Ukraine \\ ${ }^{3}$ AGH University of Science and Technology, Department of Drilling and Geoengineering, \\ 30 A. Mickiewicza St, 30-059, Krakow, Poland
}

\begin{abstract}
The gravimetric method was used to determine the corrosion rate of a pipe for coiled tubing. Scanning electron and optical microscopy were used to study the microstructure and to determine the nature of corrosion damages. It has been found that corrosion processes of different nature occurred in the studied systems "metal-environment", in particular, in acid solutions, corrosion was caused by the of hydrochloric acid and the ambient temperature of $70^{\circ} \mathrm{C}$. In solution with a smaller acid content, along with the general corrosion, there is a significant localization of the corrosion process (deep corrosion damage is formed: macro pitting and corrosion ulcers). The general corrosion was observed in the $\mathrm{HCl}$ solution (13 mass \%), which destroys the pipe walls after $576 \mathrm{~h}$ of exposure. The neutral solutions caused the general corrosion of smaller intensity in comparison with the acidic environments, even taking into account the temperature factor. The surface-active substances or petroleum products that are present in the solutions, form barrier films on the steel surface, which prevent the access of corrosive components from the environment to the surface of the material, especially during the short exposure time. With the increase of the exposure at the elevated temperatures, the barrier films break down and the steel surface undergoes the general corrosion.
\end{abstract}

\section{Introduction}

One of the main current trends in the global gas and oil industry is to enhance the efficiency of hydrocarbons production. Today, there are various ways to increase the efficiency of gas and oil production: the influence on reservoirs, the use of new technologies for drilling wells, modern equipment for overhaul and restoration of wells, etc.

However, a special place among the above methods is occupied by "coiled tubing" (CT) technologies, which are based on the use of a very long metal pipe. They have high economic efficiency, are in a state of continuous development and improvement $[1,2]$, and

*Corresponding author: syrotyuk@ipm.lviv.ua 
there exists a certain international association to coordinate these efforts (Intervention \& Coiled Tubing Association (ICoTA) https://www.icota.com/).

The main element of the whole complex of equipment is a welded metal pipe with a length of 3-9 km (or more), wound on a drum. It should be noted that pipe CT works in the elastic-plastic area of deformation, and this causes special requirements for the quality of the pipe, and, consequently, to the characteristics of the pipe material and production technology. Nevertheless, as a result of long-term operation, local destruction of pipes is possible, which will cause an emergency situation [3, 4].

CT pipes work under cyclic bending loads and combined action of aggressive working environments [4], which contributes to the manifestations of corrosion [5, 6]. At the same time, localized metal pipe corrosion is characterized by the highest velocities, especially under the action of cyclic and bending loads [7].

The combined effect of fatigue and corrosion is one of the main causes of emergencies before the depletion of the resource of the CT pipes, caused by surface damage and at loads much lower than permissible $[3,4]$. The decrease in the resistance to the cracks propagation in the material, and consequently the decrease in the resource of the CT pipes, is most likely due to the formation of fatigue cracks from surface defects $[8,9]$ (mechanical defects or corrosion damage) at high cross-sectional stresses.

According to the statistic data of oil and gas companies operating in Ukraine and actively using CT technologies, the most common damages of pipes in their practice are:

1. Mechanical damage:

- damage by holding dies;

- erroneous closing of the valve on the fountain fittings;

- emergency lift with injector defects.

2. Operational damage:

- blowholes on the pipe (depressurization of the pipe by the violation of the washing technology);

- buckling of the pipe caused by the excess of differential pressure;

- pits on the pipe surface, formed by the violation of the technology of leaching of propane.

3. CT pipes damage due to acids or gas hydrates:

- fracture of the pipe by the violation of chemical treatment technology (Fig. 1);

- corrosion damage during long-term storage of pipe with violation of preservation technology;

- gas hydrates cause of internal pitting corrosion of CT pipes, which is observed as the neutral and so the acidic environments.

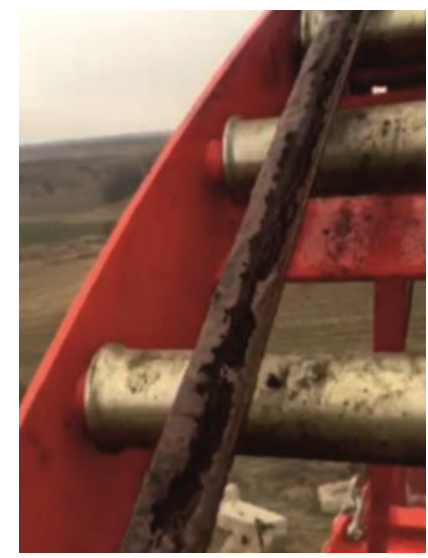

Fig. 1. Corrosion damage to the CT pipe after acid jobs. 
4. Damage caused by long operation and violation of terms for periodic control of CT pipes state:

- fatigue damage, flaw;

- break, fractures of the CT pipes (excess of the number of tripping operations (TO)).

Given the complexity of the TO, the injection of reagents [10], and compliance with the technology of work, attention is mainly paid to the number of TO. Cases of mechanical or fatigue damage during winding and unwinding are investigated, and much less attention is paid to the issue of corrosion [11-13].

\section{Methods}

QT-800 steel [14], from which CT pipes are made, was tested. It is high-strength low-alloy steel [15] with alloying additives to ensure resistance to atmospheric corrosion. The nominal chemical composition meets the requirements of the standard API 5ST CT80: 0.150 mass \% C; $\leq 0.430 \mathrm{Si} ; 0.820 \mathrm{Mn} ; 0.570 \mathrm{Cr} ; \leq 0.019 \mathrm{P} ; \leq 0.001 \mathrm{~S} ; \leq 0.220 \mathrm{Cu} ; \leq 0.08 \mathrm{Ni} ; 0.19 \mathrm{Mo} ; 0.017$ $\mathrm{Nb}$; 0.010-0.020 Ti; 0.015-0.040 V; 0.070-0.120 Al, remainder - Fe. Mo and $\mathrm{Nb}$ increase the hardenability of steel and improve the conversion of ferrite. Steel structure: polygonal ferrite and granulated bainite [16]. Microstructural features of steel are shown in Fig. 2.

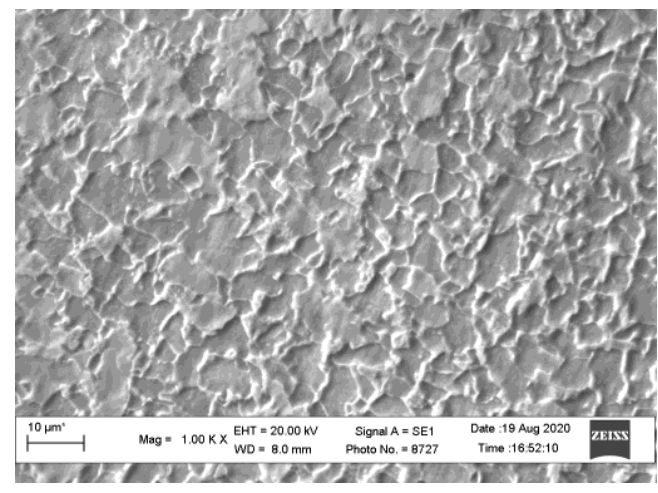

Fig. 2. The structure $(\times 1000)$ of QT- 800 steel after etching.

Such corrosive environment were used:

- I - acid solution, recipe 1 (low content $\mathrm{HCl}+$ complex of additives);

- II - acid solution, recipe 2 (13 mass $\% \mathrm{HCl}+$ complex of additives);

- III - special aqueous solution NS4 [17], modeling groundwater in neutral soils $\left(0.122 \mathrm{~g} / 1 \mathrm{KCl} ; 0.483 \mathrm{~g} / 1 \mathrm{NaHCO}_{3} ; 0.137 \mathrm{~g} / \mathrm{CaCl}_{2} ; 0.131 \mathrm{~g} / 1 \mathrm{MgCl}_{2}\right)$;

- IV - formation water + SAS (surface-active substances);

$-\mathrm{V}-$ condensate from the Yablunivsky oil and gas condensate field.

Corrosion investigations. Samples for tests for general corrosion [18-20] were cut from a CT pipe $\varnothing 38.1 \times 2.77 \mathrm{~mm}$ by a technology, which made it possible to consider the peculiarities of CT production. They had the same shape and size, they were ground (to roughness $R_{a}=0.63 \mu \mathrm{m}$ ), degreased with acetone, dried, and kept in a desiccator for $2 \mathrm{~h}$.

The samples were completely immersed in a corrosive medium and kept in a thermostat at a temperature of $70^{\circ} \mathrm{C}$ to reproduce real operating conditions [21,22].

The corrosion rate $K_{m}$ was determined by the gravimetric method after exposure to a corrosive environment under natural aeration and removal of corrosion products. Weighed on the analytical weighing stales with an error of $\pm 0.0001 \mathrm{~g}$. To calculate the corrosion rate the known formula was used: 


$$
K_{m}=\frac{\Delta m}{S \cdot t}, \mathrm{~g} /\left(\mathrm{cm}^{2} \cdot \mathrm{h}\right),
$$

where $\Delta m$ - the change in mass of the sample after exposure to a corrosive environment and the removal of corrosion products $(\mathrm{g}) ; S$ - the surface area of the sample $\left(\mathrm{cm}^{2}\right) ; t$-duration of exposure (h). EVO-40XUP (Zeiss) scanning electron microscope was used to determine the nature of corrosion damage.

\section{Results and discussion}

According to the results of studies of total corrosion in five working solutions, it was found that the corrosion rate in acidic [22, 23] solutions (I, II) is significantly higher than in neutral [24] (III, IV, and V). For ease of analysis, the results of corrosion studies are presented separately for acidic and neutral working solutions.

The highest corrosion rate (Fig. 3) was observed in solution II consisting of 13 mass \% $\mathrm{HCl}$, this is the most aggressive solution among the studied. Here, an increase in the corrosion rate was observed in time up to $288 \mathrm{~h}$ of exposure, after which the corrosion rate decreased slightly. This extreme nature of the change in the corrosion rate is due to several factors. The corrosion process is a surface phenomenon, in which the metal surface dissolves. Since the primary surface area is taken into account when calculating the corrosion rate, then under an extremely active working environment (13 mass \% $\mathrm{HCl}$ and $70^{\circ} \mathrm{C}$ ) the active surface area will increase due to the increase of surface relief (Fig. 4) during exposure to aggressive environments. (Fig. 3).

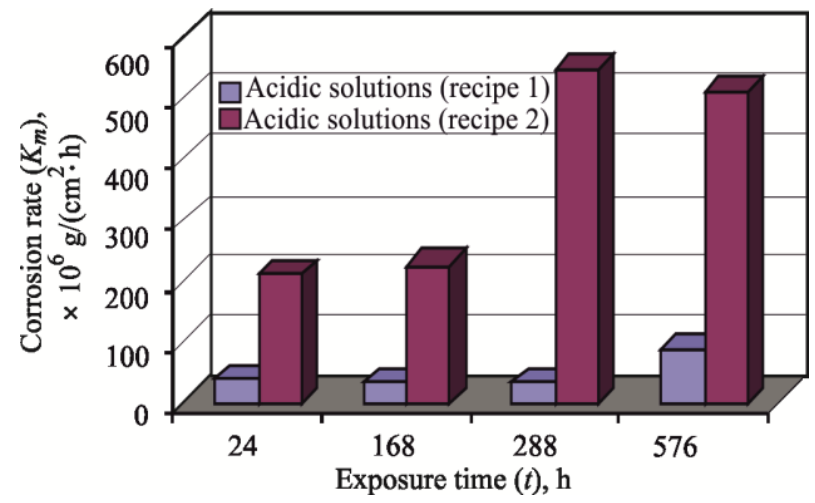

Fig. 3. The corrosion rate of QT- 800 steel vs different times of exposure in an acid corrosive environment.

After $288 \mathrm{~h}$ of exposure, the corrosion rate slightly decreases due to the solution depletion (reduction of the proportion of free corrosive components of the solution) and reduction of the active surface area due to metal dissolution in an aggressive working environment, what is confirmed by significant weight loss of the studied sample (Figs. 3 and 4). The steel corrosion rate in the solution I much lower compared to solution II, due to the lower aggressiveness of this working environment under operating conditions. However, the corrosion process is more active in comparison with neutral working media, and shows a steady increase in rate during exposure from 24 to $576 \mathrm{~h}$, due to, as in the previous case, the increase in the active surface area of the sample during the experiment. Here, as in the previous case, the process of general corrosion is observed which is reflected in a significant loss of material over time, and a significant localization of the corrosion process (deep corrosion damage to the surface of samples such as micro pitting and corrosion pits). 


\section{Corrosive environment № I}
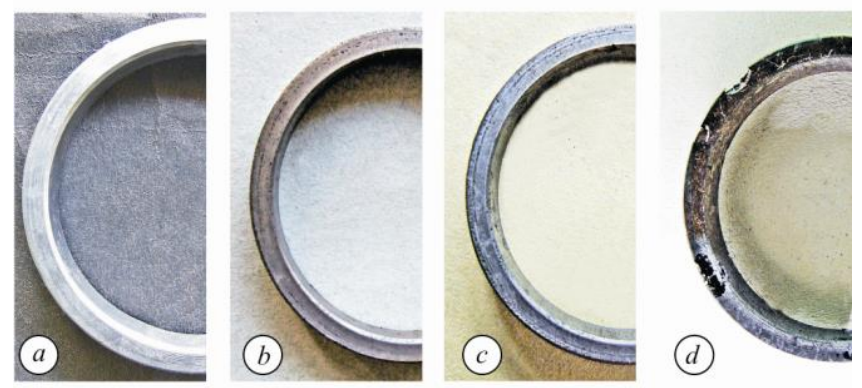

Corrosive environment № II
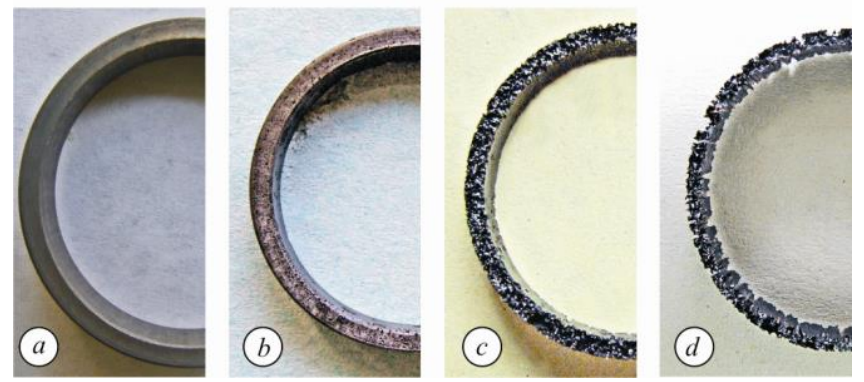

Fig. 4. The surface of the samples after exposure to acidic solutions recipe 1 and recipe 2 duration $24 \mathrm{~h}(\mathrm{a}), 168 \mathrm{~h}(\mathrm{~b}), 288 \mathrm{~h}(\mathrm{c})$, and $576 \mathrm{~h}$ (d).

However, in this case, the process of local corrosion is more pronounced compared to the previous one, which is due to less activity of the working environment, and consequently less intensity of the general corrosion process.

A classical process of corrosion rate decrease during exposure in solution III was observed (Fig. 5) due to the reduction of the active surface over time because of the passive oxide and hydroxide film formation on the metal surface. Here, the corrosion rate is higher as compared to standard experimental conditions, resulting from the high ambient temperature $\left(70^{\circ} \mathrm{C}\right)$.

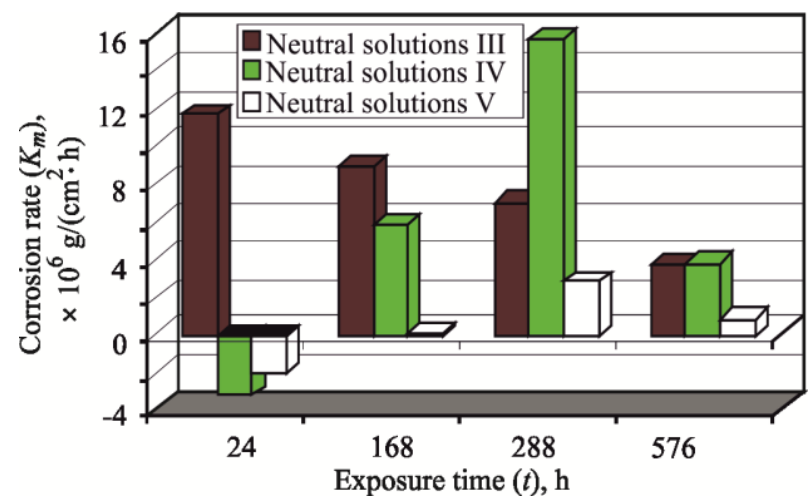

Fig. 5. The corrosion rate of QT- 800 steel vs different times of exposure in the neutral corrosive environment.

The presence of SAS in environment IV influences the steel corrosion (Fig. 5) in the working environment. During the first 24 hours, barrier films are formed on the steel surface, which is reflected in the conditionally negative corrosion rate. The corrosion rate was 
determined by the gravimetric method, so the mass of the samples after exposure to $24 \mathrm{~h}$ in the working environment is greater than the initial one, due to the deposition of SAS on the material surface and the formation of a barrier film. It makes it difficult for corrosive active components of the environment to access the surface of the material. As exposure to high temperatures increases, the barrier films gradually break down. After exposure for $288 \mathrm{~h}$, the corrosion rate is higher even than NS4 (environment III) after $24 \mathrm{~h}$ (Fig. 6).
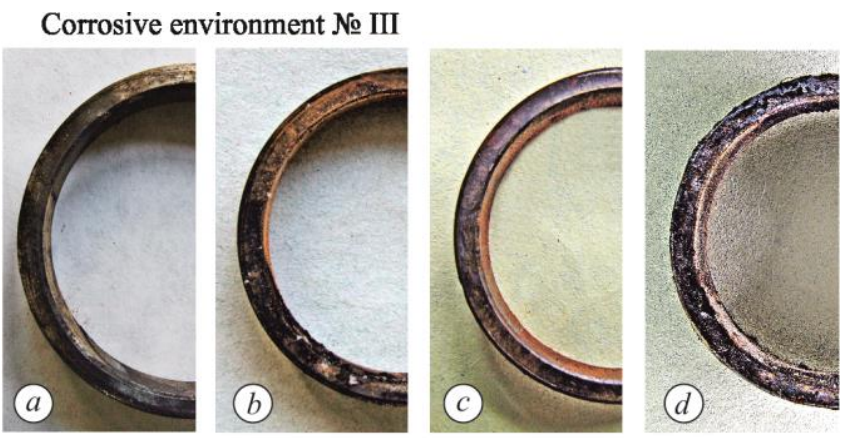

Corrosive environment № IV
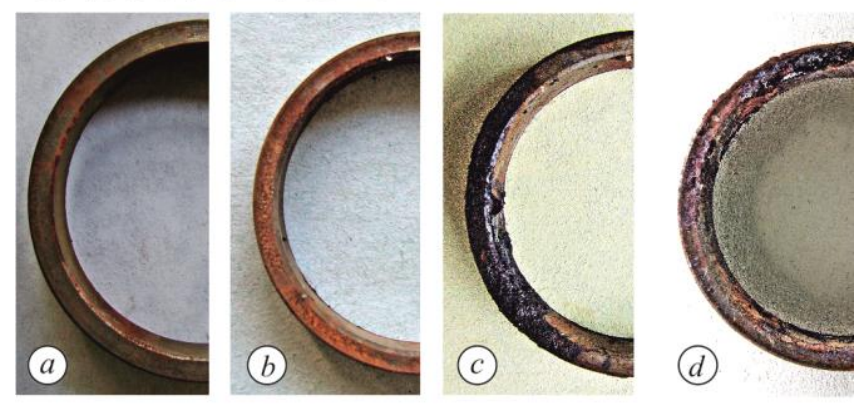

\section{Corrosive environment № V}
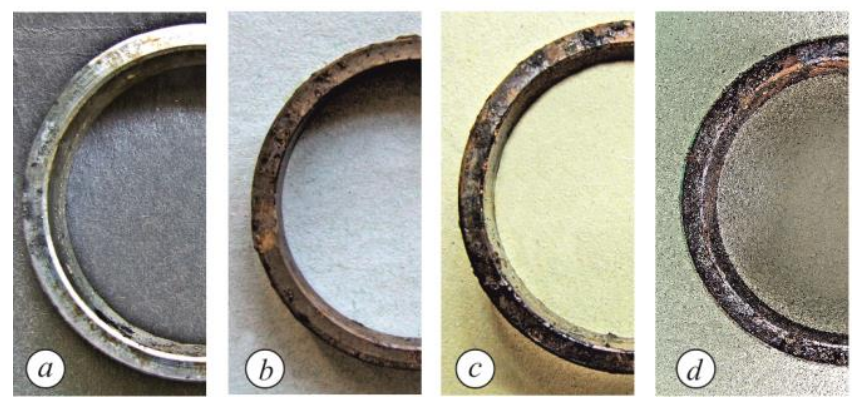

Fig. 6. The surface of the samples after exposure in the neutral solutions (III, IV, V) duration $24 \mathrm{~h}$ (a), $168 \mathrm{~h}(\mathrm{~b}), 288 \mathrm{~h}(\mathrm{c})$, and $576 \mathrm{~h}(\mathrm{~d})$.

This is due to the higher corrosion activity of the medium compared to NS4, and a fairly significant porosity of the formed barrier film at a temperature of $70^{\circ} \mathrm{C}$, which accelerates corrosion processes. After exposure to $576 \mathrm{~h}$, the corrosion rates of the test material in media III and IV, in NS4 and in formation water, respectively, are practically equalized, which is explained by the loss of barrier properties of the formed film.

Corrosion processes in the condensate from the Yablunivsky oil and gas condensate field (solution V) have similar tendencies to change the rate of the corrosion process as in 
solution IV. Presumably, such nature of the corrosion rate changes is stipulated by the same reasons as in the previous case, but this medium is less corrosive, which causes the decrease of the corrosion rate indicators in 4-6 times.

\section{Conclusions}

It has been found that corrosion processes of different nature occurred in the studied systems "metal - environment", In particular, in acid solutions, corrosion was caused by the content? of hydrochloric acid and the ambient temperature of $70^{\circ} \mathrm{C}$. In solution with a smaller acid content, along with the general corrosion, there is a significant localization of the corrosion process (deep corrosion damage is formed: macro pitting and corrosion ulcers). The general corrosion was observed in the $\mathrm{HCl}$ solution (13 mass \%), which destroys the pipe walls after $576 \mathrm{~h}$ of exposure.

The neutral solutions caused the general corrosion of smaller intensity in comparison with the acidic environments, even taking into account the temperature factor. The surfaceactive substances or petroleum products that are present in the solutions, form barrier films on the steel surface, which prevent the access of corrosive components from the environment to the surface of the material, especially during the short exposure time. With the increase of the exposure at the elevated temperatures, the barrier films break down and the steel surface undergoes the general corrosion.

In practice, after finishing work with acid solutions, it is necessary to neutralize their action with alkalis, since the residues of acid solutions or their vapors can accumulate in the coils of CT pipes and favor the development of local corrosion damages.

Continuing to work in this direction, the authors want to consider in more detail the action of gas hydrates on the corrosion resistance $[18,19,24]$ of CT pipes. Especially, action acidic gases such as $\mathrm{H}_{2} \mathrm{~S}$ and $\mathrm{CO}_{2}$, which are components of gas hydrates, and dissolve in water, can accelerate the internal pitting corrosion of CT pipes.

The presented study was conducted within the project R6.1 "Development of new methods for improving reliability and durability of the flexible pipes for gas and oil extraction by the coiled tubing technologies" of the Targeted Programme of Scientific Research of National Academy of Sciences of Ukraine "Reliability and durability of materials, constructions, equipment and structures" ("RESURS-2").

\section{References}

1. Padron, T., \& Craig, S.H. (2018). Past and present coiled tubing string failures - history and recent new failures mechanisms. Society of Petroleum Engineers - SPE/ICoTA Coiled Tubing and Well Intervention Conference and Exhibition 2018. https://doi.org/10.2118/189914-MS

2. Myatt, J., Lynn, S., Craig, S., Murphy, S., Correa, P., \& Padron, T. (2015). Challenging conventional fluid practices for coiled tubing drilling. Society of Petroleum Engineers - Coiled Tubing and Well Intervention Conference and Exhibition 2015, 317-330. https://doi.org/10.2118/173661-MS

3. Zhou, Z., Tan, J., Wan, F., \& Peng, B. (2019). Improvement and determination of the influencing factors of coiled tubing fatigue life prediction. Advances in Mechanical Engineering, 11(9), 168781401988013. https://doi.org/10.1177/1687814019880131

4. Sherman, S., Majko, S. M., \& Otto, J. (2020). High strength coiled tubing - how is fatigue life affected by slip damage? Society of Petroleum Engineers - SPE/ICoTA Well Intervention Conference and Exhibition 2020. https://doi.org/10.2118/199859-MS

5. Wei, X, Dong, J., Chen, N., Yadav, A.P., Ren, Q., Wei, J., \& Ke, W. (2021). Effects of bentonite content on the corrosion evolution of low carbon steel in simulated geological disposal environment. Journal of Materials Science \& Technology, (66), 46-56. https://doi.org/10.1016/j.jmst.2020.04.071 
6. Zhao, W., Xiao, J., Saiood, H.A., Otaibi, A.B., Huang, J., \& Chang, F.F. (2020). Chemical solution to ESP packer penetrator corrosion problem. International Petroleum Technology Conference. https://doi.org/10.2523/iptc-19633-abstract

7. Li, L., Shen, Z.X., \& Wang, P. (2013). Research the coiled tubing deformation under internal pressure and cyclic bending. Applied Mechanics and Materials, (421), 62-65. https://doi.org/10.4028/www.scientific.net/amm.421.62

8. Akid, R., Dmytrakh, I.M., \& Gonzalez-Sanchez, J. (2006). Fatigue damage accumulation: The role of corrosion on the early stages of crack development. Corrosion Engineering Science and Technology, 41(4), 328-335. https://doi.org/10.1179/174327806X139108

9. Syrotyuk, A.M., \& Dmytrakh, I.M. (2014). Methods for the evaluation of fracture and strength of pipeline steels and structures under the action of working media. Part I. influence of the corrosion factor. Materials Science, 50(3), 324-339. https://doi.org/10.1007/s11003-014-9724-5

10. Ziaja, J., Stryczek, S., \& Jamrozik, A. (2017). Sealing slurries limiting natural gas exhalations from the annular space of a wellbore [Zaczyny uszczelniajaące ograniczajaące eltshalacje gazu ziemnego z przestrzeni pierścieniowej otworu wiertniczego]. Przemysl Chemiczny, 96(5), 990-992. https://doi.org/10.15199/62.2017.5.9

11. Syrotyuk, A., Vytyaz, O., \& Ziaja, J. (2017). Damage to flexible pipes of coiled tubing equipment due to corrosion and fatigue: methods and approaches for evaluation. Mining of Mineral Deposits, 11(4), 96-103. https://doi.org/10.15407/mining11.04.096

12. Duque, L.H., Guimarães, Z., Berry, S.L., \& Gouveia, M. (2008). Coiled tubing and nitrogen generation unit operations: Corrosion challenges and solutions found in brazil offshore operations. Society of Petroleum Engineers - Coiled Tubing and Well Intervention Conference and Exhibition 2008, 240-254. https://doi.org/10.2118/113719-MS

13. Ziaja, J., Jamrozik, A., \& Wiśniowski, R. (2019). Modified drilling fluids for workover jobs in oil wells. International Multidisciplinary Scientific GeoConference Surveying Geology and Mining Ecology Management, 19(1-2), 1017-1024. https://doi.org/10.5593/sgem2019/1.2/S06.129

14. Hagianu, A., Nae, I., Ionescu, G.C., \& Ripeanu, R. G. (2020). Research on mechanical and geometrical characteristics of materials used for flexible tubing production. IOP Conference Series: Materials Science and Engineering, (724), 012004. https://doi.org/10.1088/1757$\underline{\text { 899X/724/1/012004 }}$

15. Ghiasi, H. (2018). Evaluation of microstructural effects on mechanical properties of CT80 grade coiled tubing steel. Scientia Iranica, 25(4), 2155-2161. https://doi.org/10.24200/sci.2018.20677

16. Zhou, L., Jiang, B., Li, M., Yuan, F., Zhang, C., \& Liu, Y. (2014). Microstructure control of nonquenched and tempered ct 80 grade coiled tubing steel. Acta Metallurgica Sinica (English Letters), 27(3), 464-468. https://doi.org/10.1007/s40195-014-0063-1

17. Dmytrakh, I.M., Smiyan, O.D., \& Syrotyuk, A.M. (2010). Experimental study of fatigue crack growth in pipeline steel under hydrogenating conditions. 18th European Conference on Fracture: Fracture of Materials and Structures from Micro to Macro Scale.

18. Poberezhny, L., Hrysanchuk, A., \& Grytsuliak, H. (2019). Influence of the gas hydrates on the corrosion rate of gas gathering pipelines. Procedia Structural Integrity, (16), 141-147. https://doi.org/10.1016/j.prostr.2019.07.033

19. Hua, Y., Barker, R., \& Neville, A. (2014). Effect of temperature on the critical water content for general and localised corrosion of X65 carbon steel in the transport of supercritical CO2. International Journal of Greenhouse Gas Control, (31), 48-60. https://doi.org/10.1016/j.ijggc.2014.09.026

20. Abdulridha, A.A., Allah, M.A.A.H., Makki S.Q. et al. (2020) Corrosion inhibition of carbon steel in $1 \mathrm{M} \mathrm{H} 2 \mathrm{SO} 4$ using new Azo Schiff compound: Electrochemical, gravimetric, adsorption, surface and DFT studies. Journal of Molecular Liquids, 315, 113690, https://doi.org/10.1016/j.ijggc.2014.09.026

21. Krueger, S., \& Schoenborn, K. (2020). New high temperature coiled tubing drilling bottom hole assembly enables slimhole re-entry drilling in challenging high temperature wells. Society of Petroleum Engineers - SPE/ICoTA Well Intervention Conference and Exhibition 2020. https://doi.org/10.2118/199842-MS 
22. Saeed, A., Hamid, S., Yakovlev, T., Sagr, H., \& Harthi, S. (2020). Worldwide first successful production logging of tri-lateral high temperature coiled tubing drilled sour gas well, performed in a single run using innovative reentrance system without whipstock guides. Society of Petroleum Engineers - SPE/ICoTA Well Intervention Conference and Exhibition 2020. https://doi.org/10.2118/199872-MS

23. Al-Nakhli, A., Arifin, M., \& Ahmed, D. (2019). Novel application of distributed temperature sensing and CT real-time downhole flow measurement tool for thermochemical treatments. International Petroleum Technology Conference 2019. https://doi.org/10.2523/19307-MS

24. Newman, K., Kelleher, P., \& Gunby, B. (2017). Optimizing CT material properties for extended reach operations. Society of Petroleum Engineers - SPE/ICoTA Coiled Tubing and Well Intervention Conference and Exhibition 2017. https://doi.org/10.2118/184749-MS 